\title{
The impact of parental health status on children's eating habits and behaviors: A narrative review
}

\author{
Maria Bogri' ${ }^{1}$ Aikaterini Kanellopoulou', Venetia Notara ${ }^{2}$, Demosthenes Panagiotakos ${ }^{1,3}$ \\ 'Department of Nutrition - Dietetics, School of Health Science \& Education, Harokopio University of Athens, Greece \\ ${ }^{2}$ Department of Public and Community Health, School of Public Health, University of West Attica, Athens, Greece \\ ${ }^{3}$ Faculty of Health, University of Canberra, ACT, Australia
}

\begin{abstract}
Although the problem of childhood obesity has been broadly documented over the last decades and characterized as one of the most significant problems of public health, the percentage of overweight and obese children remains extremely high. It is undeniable that parents contribute significantly in shaping children's dietary behavior and can be a valuable factor for implementing effective strategies. However the influence of parental health status on children's eating habits is another aspect that remains almost uninvestigated. The aim of the study is to examine to what extend parental diet-related chronic diseases affect their own but also their children dietary behavior. A literature review was conducted focusing on studies published within the last decade. The majority of studies examined,indicated a moderate to very low adherence to dietary guidelines for a specific disease, as a result children's dietary behavior is not favorably affected.Therefore we should emphasize on the importance of healthy dietary modeling especially in case of a family history of disease.
\end{abstract}

KEY WORDS: Childhood obesity, parental health, family history, dietary habits

\section{INTRODUCTION}

Nowadays it is widely known that childhood obesity has become one of the most significant problems of public health worldwide. Recent evidence show that the percentage of childhood obesity has risen up to $30 \%$ which means that one out of three children in theU.S. is classified as either overweight or obese. ${ }^{1-3}$ According to WHO in 2016, 41 million children were overweight

\section{Corresponding author:}

Prof. Demosthenes B. Panagiotakos, DrMed, FRSPH, FACE School of Health Science and Education Department of Nutrition and Dietetics Harokopio University, Athens, Greece

E-mail: d.b.panagiotakos@usa.net and obese globally. The upward trend of obesity prevalence over the last decades has been broadly confirmed despite the efforts of clinical and political makers to address the issue. ${ }^{4}$ Understanding the ongoing trends is a key factor in the implementation of effective strategies. Childhood obesity is associated with the development of several serious obesity-related co-morbidities that not only affect children's life but also increase the burden of the health care system. ${ }^{5}$ The comorbidities affect a number of systems including cardiorespiratory, endocrinologic, gastrointestinal, orthopedic and muscuskeletal. ${ }^{6}$ It's worth mentioning that the percentage of dyslipedemia in overweight children is double the

Submission: 14.03.2020, Acceptance: 18.05.2020 
The impact of parental health status on children's eating habits and behaviors: a narrative review

TABLE 1. Characteristics of studies included in this narrative review

\begin{tabular}{|c|c|c|c|}
\hline Study & Design & Sample & Results \\
\hline $\begin{array}{l}\text { Piotrowicz et } \\
\text { al.,2015 (20) }\end{array}$ & Cross-sectional & $\begin{array}{l}113 \text { patients, } 90 \text { males, age } \\
48 \pm 9 \text { years }\end{array}$ & $\begin{array}{l}91 \% \text { had sedentary life, none of the } \\
\text { patients followed cardioprotective } \\
\text { diet recommendations }\end{array}$ \\
\hline $\begin{array}{l}\text { Alefishat et al, } \\
2016 \text { (21) }\end{array}$ & Cross-sectional & $\begin{array}{l}900 \text { patients, } 47,8 \% \text { males, } \\
\text { age } 55.1 \pm 11.06 \text { years }\end{array}$ & $\begin{array}{l}48.4 \% \text { were non adherent to } \\
\text { medications } 90,3 \% \text { were non } \\
\text { adherent to lifestyle changes }\end{array}$ \\
\hline $\begin{array}{l}\text { Ausili et al,2017 } \\
\text { (22) }\end{array}$ & Cross-sectional & $\begin{array}{l}302 \text { patients, } 53.6 \% \text { males, } \\
\text { median age } 68 \text { years. }\end{array}$ & $\begin{array}{l}\text { Diet was the most frequent self care } \\
\text { behavior }(M=5.2[4.2-6.0]) \text { following } \\
\text { exercise, blood testing and foot } \\
\text { care. }\end{array}$ \\
\hline
\end{tabular}

\begin{tabular}{lll}
$\begin{array}{l}\text { Al-Khawaldeh } \\
\text { et al, } 2012(23)\end{array}$ & Cross-sectional & $\begin{array}{l}223 \text { patients, } 56,1 \% \text { males, } \\
\text { age } 59.9 \pm 8.4 \text { years }\end{array}$ \\
& & \\
\hline $\begin{array}{l}\text { Milas et al, } \\
2006(24)\end{array}$ & Cross- sectional & $\begin{array}{l}960 \text { hypercholesterolemic } \\
\text { patients, } 41,6 \% \text { males, mean } \\
\text { age } 43.7 \pm 16.1 \text { years for men } \\
\text { and } 44.7 \pm 16.0 \text { for women. }\end{array}$
\end{tabular}

Within a range of 0-7 medication taking was the most frequent reported behavior $(M=6.1 \pm 1.7)$, diet followed $(M=4.4 \pm 1.4)$ while less frequent were blood sugar testing $(M=1.7 \pm 2.4)$ and exercise $(\mathrm{M}=1.8 \pm 1.9)$

Dietary patterns differ between hypercholesterolaemics and nonhypercholerolaemics. The first consumed more frequently fish $(p<0.001)$, bread and cereals $(p=0.031)$, fruits and juices $(p<0.001)$ and low fat yogurt $(p<0.001)$ in contrast with the last ones.

No difference concerning dietary $\begin{array}{ll}\text { risk factors or established intakes such as total fat, saturated+ } \\ \text { disease,2180 individuals with } & \text { trans fatty acid intake, long chain }\end{array}$ disease, 2180 individuals with trans fatty acid intake, long chain
no risk factors or established $\mathrm{n}-3$ fatty acids, fiber and standard disease $>18$ years old, 1109 children 2-17 years old residing in the same house with parents carrying CVD risk factors or an established disease, 1109 other children.

$\begin{array}{ll}\text { Thomas et al, Case- control } & 6235 \text { individuals with CVD } \\ 2017 \text { (25) } & \text { risk factors or established } \\ & \text { disease, } 2180 \text { individuals with } \\ \text { no risk factors or established } & \text { disease }>18 \text { years old, } 1109 \\ \text { children } 2-17 \text { years old } \\ \text { residing in the same house } \\ \text { with parents carrying CVD } \\ \text { risk factors or an established } \\ \text { disease, } 1109 \text { other children. }\end{array}$
drinking $(p>0.05)$ was detected between adults with CVD risk or established disease and adults with no risk factor or established disease. Different intakes between the two groups was detected only for total energy and sodium $(p<0.05)$. No difference was detected for children residing in the same household with affected adults in contrast with other children.

\section{Osadnik et Case-Control Study Healthy young adults 18-35} $\mathrm{al}, 2018$ (MAGNETIC Project) years old, 351 with family history of P-CAD and 338 without
Subjects with family history of P-CAD showed higher adherence by $31 \%$ and $25 \%$ to 'westernized traditional' DP (OR: 1.31, $(95 \% \mathrm{Cl})$ : $1.12-1.53 ; p<0.005$; and adjOR 1.25, 95\% Cl: 1.06-1.48; $p=0.007$; respectively).

Comments

$73 \%$ required partial diet modification $27 \%$ required complete diet modification

Educational levels $(p<0.023)$, knowledge scores $(p=0.001)$, and attitudes toward health $(p \leq 0.001)$ were positively associated with better adherence to lifestyle changes score.

$50 \%$ of the subjects did not have their diabetes under control only $42 \%$ attended diabetes educational programs

Hypercholesterolaemic participants seemed to be more consistent with dietary guidelines.
Young adults follow unfavorable dietary habits concerning the P-CAD family history and health risk. 
TABLE 1. Characteristics of studies included in this narrative review (continued)

\begin{tabular}{|c|c|c|c|c|}
\hline Study & Design & Sample & Results & Comments \\
\hline $\begin{array}{l}\text { Haycraft et } \\
\text { al,2017 }\end{array}$ & Case-control & $\begin{array}{l}437 \text { mothers with their } 2-6 \\
\text { years old children, } 249 \text { health } \\
\text { weight, } 188 \text { overweight/ } \\
\text { obese, age } 34 \pm 5.7 \text { years }\end{array}$ & $\begin{array}{l}\text { Overweight/obese mothers } \\
\text { provided less healthy food } \\
\text { environment ( } p=0.021) \text {, reported } \\
\text { giving their child more control } \\
\text { around eating ( } p<0.01) \text {, encourage } \\
\text { less variety around food ( } p=0.021) \text {, } \\
\text { showed less healthy food } \\
\text { modeling }(p<0.01 \text { ) in contrast with } \\
\text { healthy weight mothers }\end{array}$ & \\
\hline $\begin{array}{l}\text { Ejtahed et } \\
\text { al,2018 }\end{array}$ & Cross-sectional & $\begin{array}{l}14400 \text { students, } 7-18 \text { years } \\
\text { old with one of their parents } \\
\text { aged } 44.2 \pm 7.1 \text { fathers, } \\
38.1 \pm 6.5 \text { mothers }\end{array}$ & $\begin{array}{l}\text { The risk of excess weight (OR: } 1.30 \text {, } \\
95 \% \mathrm{Cl}: 1.17-1.44) \text {, obesity (OR: } \\
\text { 1.36, } 95 \% \mathrm{Cl}: 1.18-1.59) \text {, abdominal } \\
\text { obesity (OR: } 1.16,95 \% \mathrm{Cl}: 1.05-1.29) \\
\text { and elevated BP (OR: } 1.17,95 \% \mathrm{Cl} \text { : } \\
\text { 1.04-1.31) were higher in students } \\
\text { whose parents had excess weight } \\
\text { compared with other students. }\end{array}$ & \\
\hline
\end{tabular}

percentage in overall pediatric population while diabetes is one of the most common chronic diseases of childhood and obesity enhances the prevalence. ${ }^{7}$ Concerning cardiovascular diseases,childhood nutrition is highly linked to increased coronary heart disease risk in adulthood. ${ }^{8}$ Parents are commonly regarded as the key influence in shaping children's dietary behavior and eating habits. Parents influence their children either by their own dietary intake or by the food parenting practices they have been using. First of all parents act as food models and parental food intake behaviors are observed and eventually adopted by children. ${ }^{9}$ Through the process of modeling and mimicry,children's dietary intake is affected by the children's perception that their parents'eating habitsare the most appropriate. ${ }^{9}$ Experimental studies have shown that children are more likely to eat unfamiliar foods after they have seen a nother person consuming that food, especially if it is their parents. ${ }^{10}$ Parent -child correspondence has been reported in several cross-sectional studies examining the intake of healthy and unhealthy foods indicating a strong correspondence, especially for mothers. ${ }^{11-13}$ Although common genetics may contribute in parent-child correspondence intakes, environmental factors such as food availability and food modeling are stronger moderators especially among younger children. This hypothesis is confirmed by a large population-based twin study indicating the shared environmental influences to be the major determinants of dietary behavior in young children. ${ }^{14}$ Food parenting practices (FPP) are techniques or behaviors used by parents to affect their children's dietary behavior. FPP are divided into three main categories: coercive control (pressure to eat, threats and bribes etc.), structure (rules and limits, limited choices, monitoring etc) and autonomy support (nutrition education, child involvement, praise, negotiation etc). ${ }^{15}$ Each FFP has a different impact on children's dietary behavior although a detailed review of their results runs beyond the scope of this review.

Another important factor to consider is that dietary patterns adopted in childhood remain stable through adulthood, emphasizing the importance of early interventions in children especially younger than 12 years old before patterns are less likely to change. ${ }^{16}$ In addition it has been proved that behaviors adopted through parents'own behavior have a strong lasting effect even when children have left their home. ${ }^{17}$

Multiple factors lead to overweight and obesity in childhood and thereby influence the recommendations for management. One significant approach to tackling childhood obesity and disordered eating behaviors is to understand the most important modifiable determinants of healthy eating behaviors in early life and implement effective strategies. Parental influence on child's dietary behavior is a valuable tool of guiding interventions preventing unhealthy dietary behavior and development of overweight and obesity. ${ }^{18}$ Obesity prevention efforts should focus on healthy family based lifestyle modifications. ${ }^{19}$ The condition of parents' health and its impact on their own but also on their children's dietary intake has not been adequately examined. Thus, the aim of this review is to evaluate the association between the parents' health status (i.e., having a chronic disease) and the impact this condition may have on their children's eating behavior. 


\section{METHODS}

The research studies included in the review were published in English and were selected after a thorough review of the existing literature from the scientific database PubMed (https://pubmed.ncbi.nlm.nih.gov/). The literature review focused on studies published within the last decade (i.e 2010-2020) with just one exception concerning hypercholestelaemic patients (2006) since more recent evidence was not found. The keywords used during the search procedure were: childhood AND/OR overweight / obesity, parents, parents' health; children; family history. In addition, the reference lists of the retrieved articles were used in order to find additional relevant studies.Studies were considered eligible for inclusion in the present review provided that they were carried out in patients with an established disease or at high risk and that the age of the patient was $>18$ and $<60$ years old so that children are more likely to live in the same household with their parents. Due to the limitation of the existing literature, all types of studies were included, such as cross-sectional, case-control, and observational studies. The exclusion criteria included studies that were not written in English and those who included healthy parents.

\section{RESULTS}

\section{The impact of parents' health status on their eating behavior.}

In order to examine the effect of parents' health on children's dietary behavior, it was necessary to first examine the way parents' health condition affects their own dietary habits.A few studies have examined the impact of dietrelated diseases on patients eating behavior. In particular Piotrowicz et al., assessed the self-reported health-related behaviors and dietary habits of patients with the metabolic syndrome (MetS). A sample of 113 patients with confirmed characteristics of the syndrome participated in the study. Leading characteristics were central obesity (100\%), following respectively family history of CAD, elevated LDL and hypertension while the vast majority of the sample (85\%) presented at least moderate cardiovascular risk according to the European Society Cardiology (ESC) SCORE system. ${ }^{20}$ Diet quality was assessed using three methods: $24-\mathrm{h}$ recall, diet history questionnaire and the Healthy Eating Index. The study findings were quite impressive revealing that $85 \%$ of the patients were not aware of the dietary recommendations for $\mathrm{CV}$ risk reduction, they had a disturbed meal pattern and an exceeded energy intake leading to the result that $73 \%$ of the patients required a partial and $27 \%$ a complete diet modification. ${ }^{21}$ These findings are consistent with another cross-sectional study carrying a larger sample which examines the self-reported adherence of individuals in high risk of metabolic syndrome. Almost half of the participants were non-adherent to medications while the vast majority, namely $90 \%$ of the sample was non-adherent to lifestyle changes. ${ }^{22}$

In regards to diabetic patients several studies have assessed the self-care behaviors of those patients, one of which is a recent cross-sectional study by Ausili et al., investigating the self-care behaviors of patients along with the quality of life and clinical outcomes. A sample of 302 T2DM patients took part in this study and the behaviors assessed were diet, blood-testing, exercise and foot care. According to the assessment, diet was the most frequently followed behavior with the less frequent being exercise..$^{23}$ Similar studies have indicated that diet was the most common behavior among patients after medication. However, in the same study less than half of the patients had their diabetes under control. ${ }^{24}$ It is confirmed that diabetic patients recognize the significant role of a recommended healthy diet in metabolic control.

Additionally, a cross-sectional survey by Millas et al., investigating the prevalence of hypercholesterolaemiaand its relation to nutritional habits has revealed more promising results of patients' behavior. A large sample consisting of 5003 adults wasincluded in the study of which 38\% were hypercholesterolaemic. Data concerning demographic, socioeconomic characteristics and nutritional assessment were collected through telephone interview conducted by an expert. Hypercholesterolaemic patients were following a more favorable diet consisting of more frequent consumption of fish, bread and cereals, fruit and juices and low fat dairy products in contrast to non cholesterolaemic participants. The first seemed to be more consistent with dietary guidelines. ${ }^{25}$

\section{The association of parents' health and their children's dietary behavior.}

Two studies have investigated the interaction concerning dietary behaviors between parents with a disease and their children. Specifically, Thomas et al., through a crosssectional study has determined whether the presence of cardiovascular disease risk factors or of an established disease influences the dietary intake of affected adults and their children living under the same roof. Data from the large Australian Health Survey were used, and information concerning dietary intake of macro- and micronutrients was collected through 24-h recall of at least eight days apart. Despite the total energy and sodium being significantly lower in adults with CVD risk or established disease, although sodium intake was still higher than recommended, no other difference was observed. The 
same result applies to children, where no difference was observed between selected nutrients and the proportion of children meeting the recommendations for selected nutrients among children who reside with an adult with CVD risk or established disease and children who not. The results indicated that evidence-based recommendations for relevant nutrients aiding in the prevention of chronic diseases such as CVD are not followed as a whole and compliance to optimal dietary intakes of adults with CVD risk or established disease remains low. Similar results were reported concerning their children, as expected since children's behavior reflects that of adults. ${ }^{26}$

Furthermore,Osadnik et al., have examined whether and how family history of Premature Coronary Artery Disease (P-CAD) affects dietary patterns of Young Healthy offspring through a case-control study. The participants were healthy young adults (ages 18-35 years old), 351 with (case) and 338 without family history of P-CAD (control). Even though we examine the impact of parents' health on children's dietary patterns it has been proved that dietary patterns established early in the life form the basis of the dietary habits followed in adulthood. Consequently, the sample of young adults is accepted. The data used were collected from the Magnetic case-control study and the dietary data from a food frequency questionnaire (FFQ6). According to the results, young healthy adults with family history of P-CAD reported higher adherence to 'westernised' traditional diet which consisted of frequent consumption of processed meats, potatoes, refined grain products, red meats, sweet and snacks. As it is highlighted by the researchers, the most possible explanation of the aforementioned results is the powerful impact of parents' behavior on children's dietary choices even once they have left home. ${ }^{27}$

\section{The impact of Overweight/Obese parents on children's eating behavior.}

The study conducted by Haycraft et al., compared the differences between healthy weight and overweight/ obese mothers on their reported feeding practices and their children's eating behavior. In total, 437 mothers with a 2-6 years old child took part in the study. Dietary intake data were collected through self-reported questionnaires. First of all, as expected, overweight/obese mothers did not demonstrate the appropriate healthy eating model, provided a less healthy home food environment, less balance and variety around food and more control around eating in contrast with healthy mothers.Overweight or obese mothers used less healthy feeding practices and as it was also indicated, they had a wrong perception of their child's eating behavior reporting that their child was more reluctant and refused to eat but not to drink. These findings emphasize the need of a better support to those mothers concerning healthy eating feeding practices. ${ }^{28}$

A recent study focusing on the association of parental obesity and children's health was conducted by Ejhated et al in 2015. 14.400 students aged 7 to 18 years old with one of their parents were included in the study. Student's and parent's questionnaire concerning anthropometric characteristics and information about dietary habits and behaviors were completed by expert health care professionals. According to the analysis, children whose parents were classified as obese or abdominal obese presented higher risk of having excess body weight, obesity, abdominal obesity as well as elevated blood pressure. Further than the underlying mechanism of common genetics, common lifestyle factors such as dietary habits and physical activity are strongly associated with this outcome. ${ }^{29}$ Although several studies have evaluated the impact of parental overweight and obesity on children'sbody weight as a result of a combination of genetic and lifestyle factors documenting similar results with the above study, they are not mentioned here as parental obesity is included as a part of disturbed health status of parents.

\section{DISCUSSION}

According to the findings of the review the existence of a diet-related disease influences in various extend the group of patients. Patients with cardiovascular disease and metabolic syndrome are the least adherent to the recommended dietary intakes while diabetic patients and patients with hypercholesterolaemia seem to be more consistent with the guidelines. A few studies have evaluated the eating behaviors of children who live in the same house with parents carrying established diseases although they tend to be similar with parental eating behavior. The main reasons that lead to low levels of adherence in patients are knowledge and the attitude towards the disease. Especially in patients with metabolic syndrome educational levels, knowledge scores and attitudes towards health were positively associated with better adherence to lifestyle changes. ${ }^{20}$ However, there is not a single approach that can be implemented in all patients to improve adherence and therefore different interventions are required for each patient. ${ }^{30}$

Parents' influence on children's dietary behavior is undeniable but the first step that has to be done so thatparents positively change their children's eating behavior is to understand and recognize the heath risk their children face either due to the family history or the parental overweight and obesity. Misclassification of weight is a common phenomenon especially among parents with 
low educational level and obese parents. False negatives are way more common than false positives and parents tend to underestimate their child's weight. ${ }^{31}$ Concerning family history and parental perception of risk for their children, a study by Petricevic et al., reported that family history of obesity or obesity-related illnesses is not related to increased recognition of overweight of their children. ${ }^{32}$ On the other hand, a study conducted by Nsiah-Kumi et al., evaluated the impact of Family history of diabetes risk in overweight children. The factors that contribute to the parental perceived risk of diabetes and CVD are parental education, child gender and race/ethnicity. Parents whose child had Family history for diabetes or CVD or was obese perceived higher risk of diabetes in overweight children than those without Family history. However, parents with low educational level, African American parents and parents of girls were less likely to perceive the increased risk of diabetes in overweight children. ${ }^{33}$

Parents should be informed about the health risk of avoiding a healthy lifestyle and be educated about the crucial role they play in shaping children's health behaviors. The importance of modeling healthy behaviors for children should be highlighted by clinicians and transmitted to parents. Healthy family-based interventions are a promising strategy for the onset of chronic diseases prevention in childhood and later in life.

\title{
ПЕРІ^НЧН
}

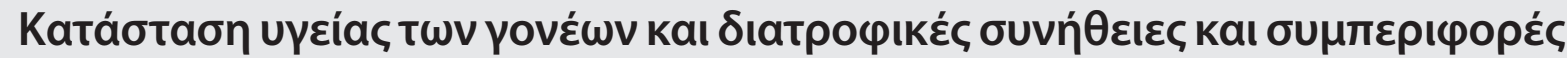

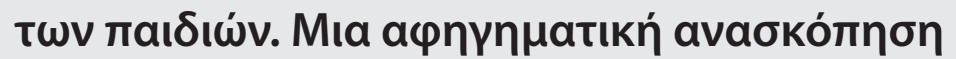

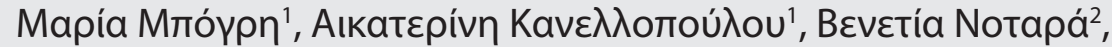

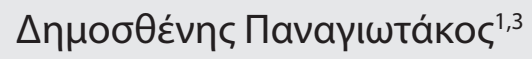

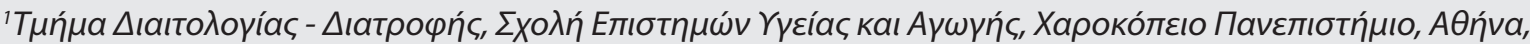

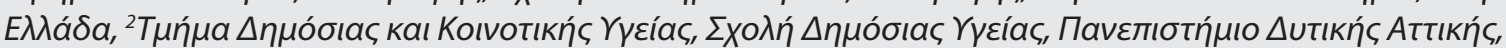

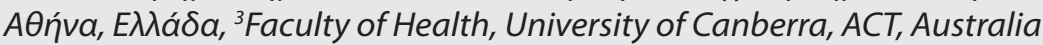

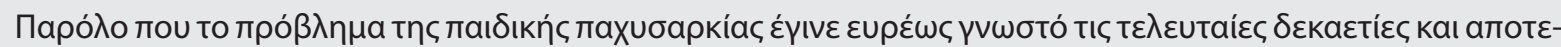

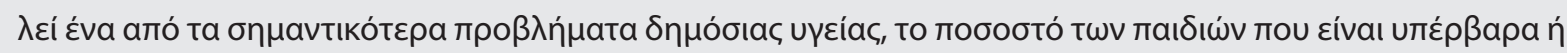

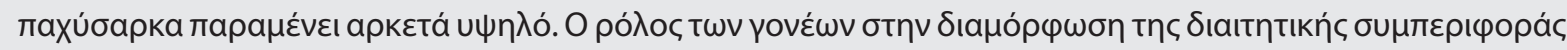

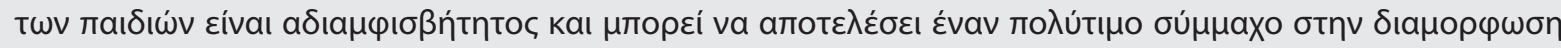

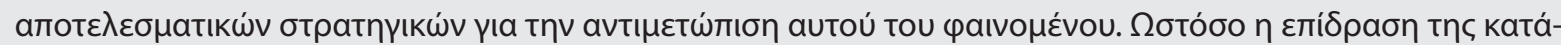

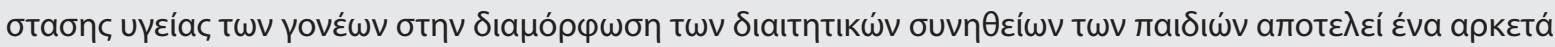

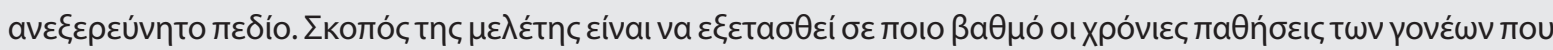

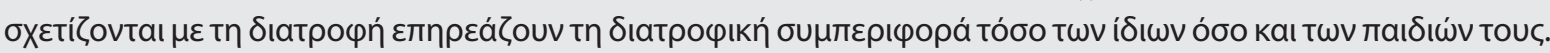

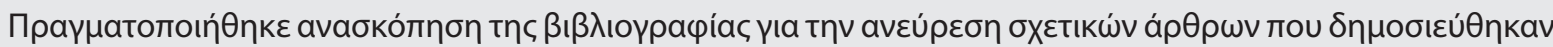

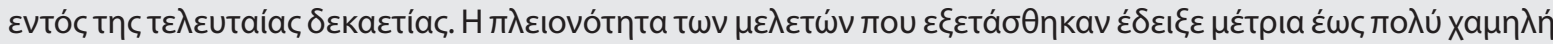

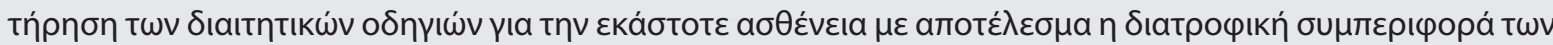

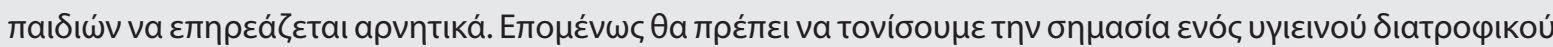

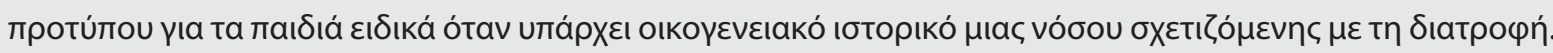

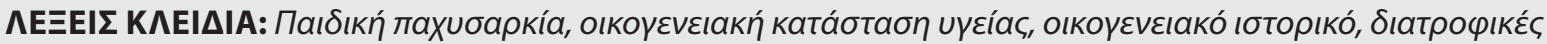

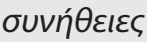

\section{REFERENCES}

1. Ogden CL, Carroll MD, Kit BK, Flegal KM. Prevalence of childhood and adult obesity in the United States, 20112012. Jama. 2014 Feb;311(8):806-14.

2. NCD Risk Factor Collaboration (NCD-RisC). Worldwide trends in body-mass index, underweight, overweight, and obesity from 1975 to 2016: a pooled analysis of 2416 population-based measurement studies in 128.9 million children, adolescents, and adults. Lancet. 2017 Dec;390(10113):2627-42.

3. Ogden CL, Carroll MD, Lawman HG, Fryar CD, KruszonMoran D, Kit BK, et al. Trends in obesity prevalence among 
children and adolescents in the United States, 1988-1994 Through 2013-2014. Jama. 2016 Jun;315(21):2292-9.

4. Skinner AC, Perrin EM, Skelton JA. Prevalence of obesity and severe obesity in US children, 1999-2014. Obesity. 2016 May;24(5):1116-23.

5. Kumar S, Kelly AS. Review of childhood obesity: From Epidemiology, Etiology, and Comorbidities to Clinical Assessment and Treatment. Mayo Clinic proc. 2017 Feb;92(2):251-65.

6. Grant-Guimaraes J, Feinstein R, Laber E, Kosoy J. Childhood Overweight and Obesity. Gastroenterol Clin North Am. 2016 Dec;45(4):715-28.

7. Expert panel on integrated guidelines for cardiovascular health and risk reduction in children and adolescents. Expert panel on integrated guidelines for cardiovascular health and risk reduction in children and adolescents: Summary report. Pediatrics. 2011 Dec;128 Suppl 5:S21356.

8. Kaikkonen JE, Mikkila V, Raitakari OT. Role of childhood food patterns on adult cardiovascular disease risk. Curr Atheroscler Rep. 2014 Oct;16(10):443.

9. Herman CP, Polivy J. Normative influences on food intake. Physiol Behav. 2005 Dec;86(5):762-72.

10. Shutts K, Kinzler KD, DeJesus JM. Understanding infants' and children's social learning about foods: previous research and new prospects. Dev Psychol. 2013 Mar;49(3):419-25.

11. Fisk CM, Crozier SR, Inskip HM, Godfrey KM, Cooper C, Robinson SM, et al. Influences on the quality of young children's diets: the importance of maternal food choices. The British journal of nutrition. 2011 Jan;105(2):287-96.

12. Fisher JO, Mitchell DC, Smiciklas-Wright H, Birch LL. Parental influences on young girls' fruit and vegetable, micronutrient, and fat intakes. J Am Diet Assoc. 2002 Jan;102(1):58-64.

13. McGowan L, Croker H, Wardle J, Cooke LJ. Environmental and individual determinants of core and non-core food and drink intake in preschool-aged children in the United Kingdom. Eur J Clin Nutr. 2012 Mar;66(3):322-8.

14. Pimpin $L$, Ambrosini GL, Llewellyn $\mathrm{CH}$, Johnson $\mathrm{L}$, van Jaarsveld $\mathrm{CH}$, Jebb SA, et al. Dietary intake of young twins: nature or nurture? Am J Clin Nutr. 2013 Nov; 98(5):1326-34.

15. Vaughn AE, Ward DS, Fisher JO, Faith MS, Hughes SO, Kremers SP, et al. Fundamental constructs in food parenting practices: a content map to guide future research. Nutr Rev. 2016 Feb;74(2):98-117.

16. Kelder SH, Perry CL, Klepp KI, Lytle LL. Longitudinal tracking of adolescent smoking, physical activity, and food choice behaviors. Am J Public Health. 1994 Jul;84(7):11216.

17. Dickens E, Ogden J. The role of parental control and modelling in predicting a child's diet and relationship with food after they leave home. A prospective study. Appetite. 2014 May;76:23-9.

18. Larsen JK, Hermans RC, Sleddens EF, Engels RC, Fisher JO, Kremers SP. How parental dietary behavior and food parenting practices affect children's dietary behavior. Interacting sources of influence? Appetite. 2015 Jun;89:246-57.

19. Anderson KL. A Review of the Prevention and Medical Management of Childhood Obesity. Child Adolesc Psy- chiatr Clin N Am. 2018 Jan;27(1):63-76.

20. European Society of Cardiology. The interactive toll for predicting and managing risk of heart attack and stroke. 2012; [cited at 2020, January 10]. Available from: www. heartscore.org.

21. Piotrowicz K, Palkowska E, Bartnikowska E, Krzesinski $P$, Stanczyk A, Biecek P, et al. Self-reported health-related behaviors and dietary habits in patients with metabolic syndrome. Cardiol J. 2015;22(4):413-20.

22. Alefishat EA, Abu Farha RK, Al-Debei MM. Self-reported adherence among individuals at high risk of metabolic syndrome: Effect of knowledge and attitude. Med Princ Pract. 2017;26(2):157-63.

23. Ausili D, Bulgheroni M, Ballatore P, Specchia C, Ajdini A, Bezze $S$, et al. Self-care, quality of life and clinical outcomes of type 2 diabetes patients: an observational crosssectional study. Acta Diabetol. 2017 Nov;54(11):1001-8.

24. Al-Khawaldeh OA, Al-Hassan MA, Froelicher ES. Selfefficacy, self-management, and glycemic control in adults with type 2 diabetes mellitus. J Diabetes Complications. 2012 Jan-Feb;26(1):10-6.

25. Milias GA, Panagiotakos DB, Pitsavos C, Xenaki D, Panagopoulos G, Stefanadis C. Prevalence of self-reported hypercholesterolaemia and its relation to dietary habits, in Greek adults; a national nutrition \& health survey. Lipids Health Dis. 2006 Mar;5:5.

26. Thomas J, Chan L, Wray A, Miller J, Mehta K, Yaxley A, et al. Does the presence of cardiovascular disease risk factors or established disease influence the dietary intake of affected adults and their children residing in the same household? A secondary analysis of the Australian Health Survey (2011-2013). BMC Cardiovasc Disord. 2017; 17:146.

27. Osadnik T, Pawlas N, Lonnie M, Osadnik K, Lejawa M, Wadolowska $L$, et al. Family History of Premature Coronary Artery Disease (P-CAD)-A Non-Modifiable Risk Factor? Dietary Patterns of Young Healthy Offspring of P-CAD Patients: A Case-Control Study (MAGNETIC Project). Nutrients. 2018 Oct; 10(10):1488.

28. Haycraft E, Karasouli E, Meyer C. Maternal feeding practices and children's eating behaviours: A comparison of mothers with healthy weight versus overweight/obesity. Appetite. 2017 Sep;116:395-400.

29. Ejtahed HS, Heshmat R, Motlagh ME, Hasani-Ranjbar S, Ziaodini $\mathrm{H}$, Taheri M, et al. Association of parental obesity with cardiometabolic risk factors in their children: The CASPIAN-V study. PLoS One. 2018 Apr;13(4):e0193978.

30. Price P. How can we improve adherence? Diabetes/metabolism research and reviews. 2016;32 Suppl 1:201-5.

31. Cullinan J, Cawley J. Parental misclassification of child overweight/obese status: The role of parental education and parental weight status. Economics and human biology. 2017 Feb;24:92-103.

32. Petricevic N, Puharic Z, Posavec M, Pavic Simetin I, Pejnovic Franelic I. Family history and parental recognition of overweight in Croatian children. Eur J Pediatr. 2012 Aug;171(8):1209-14.

33. Nsiah-Kumi PA, Ariza AJ, Mikhail LM, Feinglass J, Binns HJ, Pediatric Practice Research G. Family history and parents' beliefs about consequences of childhood overweight and their influence on children's health behaviors. Acad Pediatr. 2009 Jan-Feb;9(1):53-9. 